\title{
Efeito da temperatura no comportamento mecânico de misturas asfálticas com agregados sinterizados de argila calcinada (ASAC)
}

\author{
Effect of temperature on the mechanical behavior \\ of asphalt mixtures with sintered calcined \\ clay aggregate (SCCA)
}

Mário Jorge Andrade da Cunha ${ }^{1}$, Cleudinei Lopes da Silva ${ }^{1}$,

Cláudio Augusto de Paula Lima ${ }^{1}$, Consuelo Alves da Frota ${ }^{1}$

\author{
${ }^{1}$ Universidade Federal do Amazonas (UFAM), Grupo de Geotecnia - Av. General Rodrigo Octávio Jordão Ramos, 3000 \\ Manaus, AM \\ e-mail: mariojorgecunha@gmail.com, cleudineilopes@gmail.com, cadpl.eng@gmail.com, cafrota@ufam.edu.br
}

\begin{abstract}
RESUMO
Avaliou-se a influência da variação de temperatura no comportamento mecânico de misturas asfálticas com o agregado sinterizado de argila calcinada (ASAC), o qual foi utilizado como substituto ao seixo, em razão da carência regional de material pétreo. Participaram também da composição betuminosa, o ligante asfáltico CAP 50/70, comercializado no território amazonense; o cimento Portland CP II-Z-32, na condição de fíler; e três tipos de areia, os quais representaram o agregado miúdo, um deles oriundo da produção do ASAC e dois naturais, provenientes dos municípios de Manaus e Coari (AM). A granulometria da mistura seguiu o método de Bailey, com o fito de propiciar um melhor intertravamento das partículas. Examinou-se o comportamento mecânico em diferentes temperaturas, por meio dos ensaios de Resistência à Tração (RT), Módulo de Resiliência (MR) e Vida de fadiga. Os resultados mostraram, em geral, desempenho superior das composições asfálticas com os agregados de argila, em comparação às formulações com o agregado natural, dentro do intervalo de temperatura de 25 a $60^{\circ} \mathrm{C}$.
\end{abstract}

Palavras-chave: agregado sinterizado de argila calcinada, misturas asfálticas, resistência à tração, módulo de resiliência, vida de fadiga.

\section{ABSTRACT}

This work evaluated the influence of temperature variation on the mechanical behaviour of asphalt mixtures with sintered aggregate of calcined clay (SACC), which was used as a substitute for pebble, due to the regional shortage of stone material. Also participated in the bituminous composition: asphalt cement AC 50/70, marketed in the Amazonian territory; Portland cement, acting as filler; and three types of sand, which represented the fine aggregates, one from SACC and two from the cities of Manaus and Coari (AM). The granulometry of the blend followed Bailey's method, in order to provide a better interlocking of the particles. The mechanical behaviour at different temperatures was examined by the tests of Tensile Strength (TS), Resilient Modulus (RM) and Fatigue. The results showed a superior overall performance of the asphalt compositions with the clay aggregates, when compared to formulations with natural aggregate, within the temperature range of 25 to $60^{\circ} \mathrm{C}$.

Keywords: sintered calcined clay aggregate, asphalt mixtures, tensile strength, resilient modulus, fatigue.

\section{INTRODUÇÃO}

Intensifica-se no mundo a busca por novas tecnologias visando a produção de novos materiais para uso na construção rodoviária, notadamente pela necessidade de satisfazer o balanço econômico-ambiental, visto que os recursos naturais são finitos. Nesse contexto, a literatura mostra os agregados leves de argila expandida como substitutos de agregados naturais na construção de pavimentos asfálticos [1 a 4], além de materiais provenientes da sinterização de finos sedimentos que se acumulam em reservatórios [5]. Destacam-se, ainda, 
os estudos sobre a reutilização de resíduos da indústria cerâmica [6-10] e misturas asfálticas confeccionadas com borracha de pneus reciclados [11,12].

O Estado do Amazonas apresenta crônica deficiência de sua infraestrutura rodoviária, oriunda, em geral, da escassez superficial de material consolidado em seu perfil geológico, agravada pelas restrições impostas pela legislação ambiental. Resulta, assim, na carência de agregado pétreo. Tem-se, como exemplo, o subsolo do Município de Manaus, cuja camada superficial é constituída por $62 \%$ de argila, $34 \%$ de areia e $4 \%$ de laterita e Arenito-Manaus [13].

$\mathrm{O}$ citado ente federativo possui uma área de $1.559 .159,15 \mathrm{~km}^{2}$, ocupando o posto de Estado com maior extensão territorial na grande faixa da Floresta Amazônica. É cortado por imensa rede fluvial, crucial para o transporte na Região. Salienta-se, ainda, o regime pluviométrico, com índices elevados, da ordem de 1.800 a $2.500 \mathrm{~mm}$ por ano. Tais características, somadas àquelas acima mencionadas, mostram a considerável dificuldade para a construção civil nessa Região.

Como solução, para sobrepujar as citadas dificuldades de ordem logística, geográfica, geológica e geotécnica, as vias do Município de Manaus utilizam, em regra, o seixo (extraído do leito dos rios regionais), em função do elevado custo da brita. Porém, a extração desse material aluvionar acarreta uma remodelagem dos perfis transversais e longitudinais das calhas dos rios, modificando a dinâmica de escoamento do curso hídrico. A referida atividade pode levar ao assoreamento da calha fluvial e ao desenvolvimento prematuro de processos erosivos, a par dos incontáveis danos ambientais ao bioma e à biota locais.

Em consequência dessa conjuntura desfavorável a obras de Engenharia Civil e ao transporte rodoviário, tem-se a presença de reduzido número de rodovias federais que apresentam condições razoáveis de trafegabilidade, conforme informa a Confederação Nacional de Transportes - CNT [14].

Em decorrência dessa histórica escassez de material pétreo e, ao mesmo tempo, em virtude da elevada distância das poucas jazidas superficiais encontradas na Região, evidenciam-se expressivos os custos da construção de pavimentos, o que torna premente a busca por insumos alternativos, adequados sob o prisma tanto da economicidade quanto da proteção ambiental. Nesse contexto, mostram-se promissores materiais como o agregado sinterizado de argila calcinada (ASAC), para emprego como agregado graúdo. A literatura apresenta diversos estudos que apontam sua viabilidade técnica [15-20] e econômica para uso na massa asfáltica. SILVA e FROTA [21] assinalam ser viável a produção em larga escala do ASAC, com potencial para atender toda a demanda por agregado graúdo na região amazônica.

Destaca-se, dentre diversos estudos comparativos já realizados com o ASAC, o trabalho de SILVA [20], que obteve o módulo dinâmico uniaxial (tração/compressão com deformação controlada e tração com tensão controlada) de uma mistura com o agregado alternativo e de outras com seixo rolado (agregado convencional), apontando que os módulos dinâmicos das misturas com ASAC apresentaram-se superiores aos das misturas com seixo para baixas frequências de aplicação de carga e altas temperaturas de ensaio, mostrando que as mesmas, nessas condições que melhor retratam a situação dos pavimentos locais, estão menos susceptíveis às deformações permanentes, como afundamentos de trilhas de roda. Ressalta-se também que as misturas com o material alternativo se mostraram menos suscetíveis às variações de temperatura que as misturas com seixo rolado, tendo em vista que para baixas temperaturas e altas frequências, o processo se inverteu e as misturas com seixo passaram a apresentar maiores valores de |E*| que as misturas com ASAC.

Dentro desse contexto, estuda-se no presente estudo o comportamento mecânico de misturas asfálticas com ASAC, considerando-se a variação da temperatura. Compara-se o desempenho das misturas quando submetidas ao aumento da temperatura compatível com as condições locais, determinando-se Resistência à Tração (RT), Módulo de Resiliência (MR) e Vida de Fadiga. Também se realiza, nessa ocasião, um paralelo entre os resultados ora obtidos com os apresentados em outros trabalhos pela comunidade científica.

\section{MATERIAIS E MÉTODOS}

Foram confeccionados os agregados sinterizados de argila calcinada (ASAC) com um solo típico da Província Petrolífera de Urucu, situada a aproximadamente $650 \mathrm{~km}$ de Manaus, no Município de Coari-AM. Inicialmente foram produzidos tijolos maciços em uma empresa cerâmica no Município de Iranduba-AM, no formato $60 \times 110 \times 200 \mathrm{~mm}$ com dois furos centrais de $\emptyset 16 \mathrm{~mm}$, seguindo-se os métodos tradicionais de produção da cerâmica e temperatura de queima de aproximadamente $900^{\circ} \mathrm{C}$, sendo posteriormente britados em outra empresa, com as granulometrias equivalente à brita 0 , brita 1 , brita 2 e brita 3 .

O material argiloso foi submetido aos experimentos padronizados segundo as especificações do Departamento Nacional de Infraestrutura de Transportes (DNIT) e da Associação Brasileira de Normas Técnicas (ABNT), com a finalidade de validar seu potencial à calcinação. Foram realizados os seguintes ensaios: a) com amostra natural, análise granulométrica (ABNT NBR 7181, 1984), limite de liquidez (ABNT NBR 
6459, 1984) e limite de plasticidade (ABNT NBR 7180, 1984); e b) com os agregados sinterizados de argila, seleção expedita pelo Processo de Fervura (DNER ME 223, 1994), determinação da Perda de Massa após Fervura (DNER ME 225, 1994) e desgaste por Abrasão “Los Angeles” (DNER ME 222, 1994).

Os agregados (argila calcinada e seixo) foram submetidos aos ensaios de granulometria (ASTM C136, 1995), Gsa (Apparent Specific Gravity), Gsb (Bulk Specific Gravity), Gsb ${ }_{\mathrm{ssd}}$ (Bulk Specific Gravity in the condition Saturated Surface Dry), e absorption por meio da norma ASTM C127 (1988). Foram calculados também o desgaste pela Abrasão Los Angeles (ASTM C131, 1996) e as suas Massas Específica Compactada e Solta (Wur - Rodded Unit Weight e Wul - Loose Unit Weight), de acordo com a AASHTO T19 (1997).

Para o presente estudo foram usados três tipos de agregado miúdo: a) Areia Coari, proveniente do município de igual nome; b) Areia Mao, habitualmente empregada nas obras de engenharia da cidade de Manaus; e c) Areia ASAC, resultante da britagem dos tijolos no processo de confecção dos agregados sinterizados. A utilização deste agregado objetivou o uso de todo o material derivado da produção do ASAC, além de oferecer alternativa às areias naturais. Caracterizaram-se tais amostras de acordo com a granulometria (ASTM C136, 1995), os parâmetros Gsa (Apparent Specific Gravity), Gsb (Bulk Specific Gravity) e absorption (ASTM C128, 1993), bem como a Massa Específica Compactada (Rodded Unit Weight) pela AASHTO T19/T 19 M-93 (1997).

Foi selecionado o cimento Portland (CP II-Z-32), como fíler, usual participante das composições asfálticas regionais. Foi examinado pela massa específica real (DNER ME 085, 1994) e a granulometria para verificação da aceitação ou rejeição como material de enchimento (DNER EM 367, 1997). No caso do material asfáltico, tomou parte o ligante comercializado em Manaus pela Refinaria Isaac Sabbá (UN-REMAN), tendo sido analisado pelas especificações da Agência Nacional de Petróleo, Gás Natural e Biocombustíveis (ANP).

As composições granulométricas do tipo Concreto Asfáltico (CA) foram enquadradas segundo requisitos das especificações da Superpave para o Diâmetro Máximo Nominal (DMN) igual a 19,0 mm (SHRP, 1994a, 1994b), sendo que os percentuais relativos a cada tipo de agregado componente da mistura, inclusive o fíler, estabeleceram-se segundo o método Bailey.

Foi definido o teor de projeto conforme método do $3^{\circ} \mathrm{DRF} / \mathrm{DNIT}$, que se fundamenta nos valores do Volume de Vazios (Vv) e na Relação Betume-Vazios (RBV), bem como na especificação do método Marshall (DNER ME 043, 1995) referentes ao Vv de 3\% a 5\% e RBV de $75 \%$ a $82 \%$. As temperaturas de preparo e compactação das misturas foram estabelecidas segundo o Método de Ensaio DNER ME 004 (1994).

Antecedendo ao processo de compactação, as composições permaneceram duas horas em estufa não ventilada, em temperatura $10^{\circ} \mathrm{C}$ superior à temperatura de compactação (AASHTO PP-2), com o objetivo de simular o efeito de condicionamento de curto prazo. Empregou-se no cálculo da Densidade Específica Máxima da mistura (Gmm) o método Rice Test (ASTM D 2041, 2000). Foram determinadas as propriedades mecânicas a saber: Resistência à Tração (RT), Módulo de Resiliência (MR) e Vida de fadiga.

Foi calculada a Resistência à Tração (RT) por compressão diametral pela norma DNER ME 138 (1994). Foram realizados os experimentos no intervalo de $25^{\circ} \mathrm{C} \mathrm{a} 60^{\circ} \mathrm{C}$, com variação de 5 em 5 graus, tendo como objetivo avaliar o efeito a diferentes temperaturas, especialmente nas condições similares aquelas encontradas nos revestimentos asfálticos de Manaus. Tais ensaios foram realizados em uma Máquina Universal de Ensaios (UTM) com interface gráfica, tendo sido aplicado uma força com taxa de deslocamento controlado de $0.8 \mathrm{~mm} / \mathrm{s}$ até a ruptura. Obtida a carga de ruptura $(\mathrm{F})$, calculou-se a RT pela equação 1 . A figura 1 ilustra o equipamento, exemplificando o corpo de prova preparado para o referido teste.

$\sigma_{r}=\frac{2 F}{\pi D^{\prime} h}$

Sendo:

$\sigma_{r}=$ resistência à tração, em $\mathrm{MPa}$;

$F=$ carga de ruptura, em $\mathrm{kN}$;

$D^{\prime}=$ diâmetro do CP, em cm;

$h=$ altura do $\mathrm{CP}, \mathrm{em} \mathrm{cm}$. 


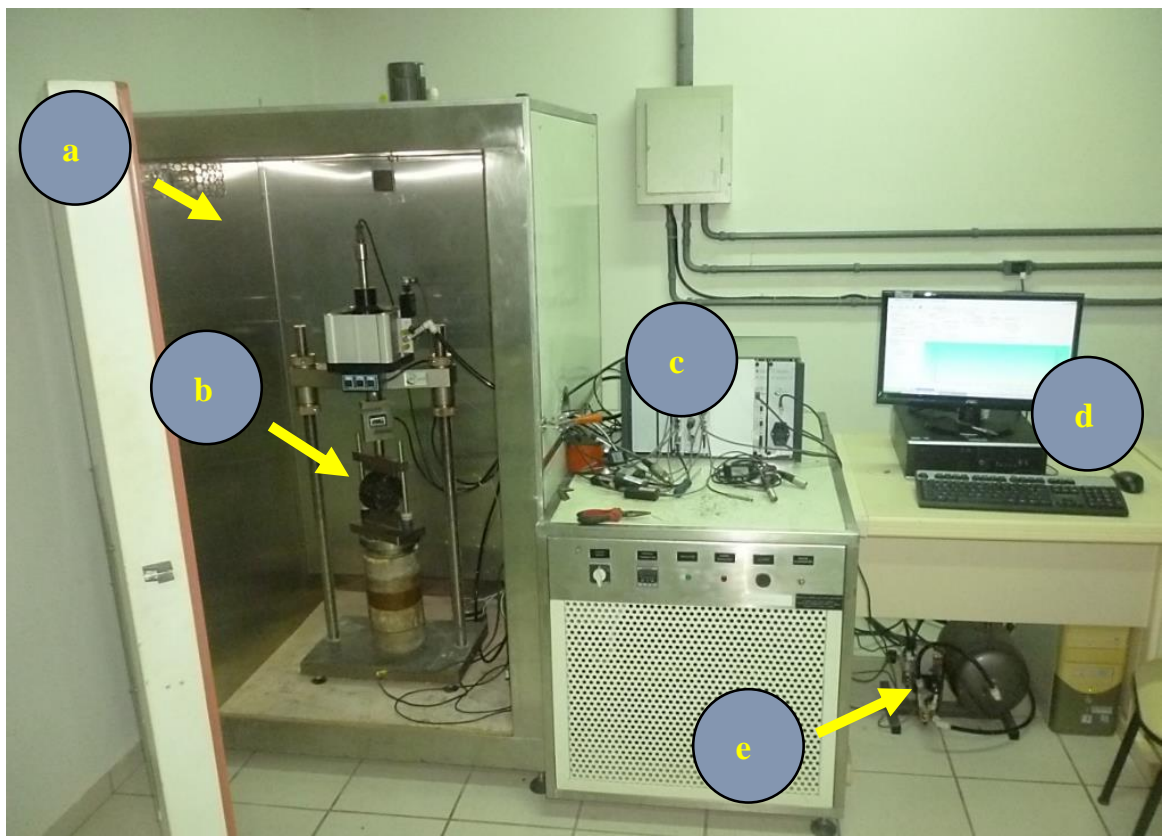

Figura 1: Máquina Universal de Ensaios: a) Câmara de temperatura; b) Célula de carga e corpo-de-prova; c) Central de controle e aquisição de dados; d) Interface computacional; e) Dispositivo de controle de pressão pneumática.

Foi utilizado também o citado equipamento (UTM) para o ensaio de Módulo de Resiliência (MR). Neste experimento os corpos de prova foram submetidos a 5, 10, 20 e 30\% da carga de ruptura relativa à RT, frequência de $1 \mathrm{~Hz}$, (tempo de carregamento de 0,1 segundos e 0,9 segundos de repouso), e intervalo de temperaturas de 25 a $60{ }^{\circ} \mathrm{C}$ (5 em 5 graus). Calculou-se o MR pela equação 2, que corresponde a razão entre a tensão de tração $(\sigma t)$, aplicada repetidamente no plano diametral vertical da amostra, e a deformação específica recuperável $(\sigma c)$.

$$
M R=\frac{\sigma_{t}}{\varepsilon_{t}}
$$

De forma analítica, o MR é definido pela equação 3:

$$
M R=\frac{F(0,976 \mu+0,2692)}{\Delta H}
$$

Sendo:

$M R=$ módulo de resiliência, em $\mathrm{MPa}$;

$F=$ carga vertical aplicada diametralmente no corpo-de-prova, em N;

$\Delta=$ deslocamento resiliente registrado para 300, 400 e 500 aplicações de carga (F), em mm;

$H=$ altura do corpo-de-prova, em mm;

$\mu=$ coeficiente de Poisson.

Nas misturas asfálticas o coeficiente de Poisson $(\mu)$ pode ser considerado independente do tipo de carregamento, alterando apenas em função da temperatura. $\mathrm{O}$ seu valor varia entre 0,35 (baixas temperaturas) a 0,50 (altas temperaturas). No Brasil é comum assumir o valor de 0,30 . Neste projeto, adotaram-se os valores para $(\mu)$ conforme Tabela 1 . 
Tabela 1: Valores para o coeficiente de Poisson em função da temperatura.

\begin{tabular}{l|l}
\hline \multicolumn{1}{c|}{ TEMPERATURA } & COEFICIENTE DE POISSON $(\boldsymbol{\mu})$ \\
\hline $25 \mathrm{a} 40^{\circ} \mathrm{C}$ & 0,30 \\
\hline $45^{\circ} \mathrm{C}$ & 0,33 \\
\hline $50^{\circ} \mathrm{C}$ & 0,35 \\
\hline $55^{\circ} \mathrm{C}$ & 0,38 \\
\hline $60^{\circ} \mathrm{C}$ & 0,40 \\
\hline
\end{tabular}

Os ensaios de Vida de fadiga foram realizados no intervalo de temperatura de 25 a $60^{\circ} \mathrm{C}$, com níveis de tensão controlada de 30, 40 e 50\% referentes ao valor da RT, e frequência de carga igual a $1 \mathrm{~Hz}$, sendo o tempo de aplicação de carga e repouso iguais 0,1 e 0,9 segundos, respectivamente. Determinou-se a Vida de fadiga como o número total de aplicações $(\mathrm{N})$ necessário ao rompimento da amostra. As tensões de tração horizontal $\left(\sigma_{t}\right)$ e de compressão vertical $\left(\sigma_{c}\right)$, no plano diametral vertical do corpo-de-prova, assim como a diferença entre elas $(\Delta \sigma)$, calcularam-se a partir das equações 4,5 e 6 .

$$
\begin{aligned}
& \sigma_{\mathrm{t}}=\frac{2 F}{\pi D H} \\
& \sigma_{\mathrm{c}}=-\frac{6 F}{\pi D H} \\
& \Delta \sigma=\sigma_{t}-\sigma_{c}
\end{aligned}
$$

$$
\begin{aligned}
& \text { Sendo: } \\
& \sigma_{t}=\text { tensão de tração horizontal, em MPa; } \\
& \sigma_{c}=\text { tensão de compressão vertical, em MPa; } \\
& F=\text { carga aplicada, em } \mathrm{N} ; \\
& D=\text { diâmetro do corpo-de-prova, em mm; } \\
& H=\text { altura do corpo-de-prova, em } \mathrm{mm} ; \\
& \Delta \sigma=\text { diferença de tensões. }
\end{aligned}
$$

\section{RESULTADOS E DISCUSSÕES}

Neste item são apresentados a caracterização física dos materiais (agregado miúdo, agregado graúdo, ligante asfáltico e fíler) e os resultados mecânicos dos ensaios de Resistência à Tração por compressão diametral, Módulo de Resiliência e Vida de fadiga das composições asfálticas, submetidas a diferentes temperaturas, com variação de $25^{\circ} \mathrm{C}$ a $60^{\circ} \mathrm{C}$, a cada $5^{\circ} \mathrm{C}$.

\subsection{Caracterização do material argiloso}

A Figura 2 ilustra a curva granulométrica do material argiloso utilizado na confecção do ASAC. Nota-se a predominância das frações argilosa e siltosa. Conforme a norma ABNT NBR 6502/1995, verifica-se um percentual de $92,0 \%$ de todo material passante pela peneira com abertura da malha igual a 0,075 mm. Portanto, atende a recomendação mínima para produção de ASAC, estabelecido pelo DNIT, igual a $85 \%$ de finos passando na citada peneira. 


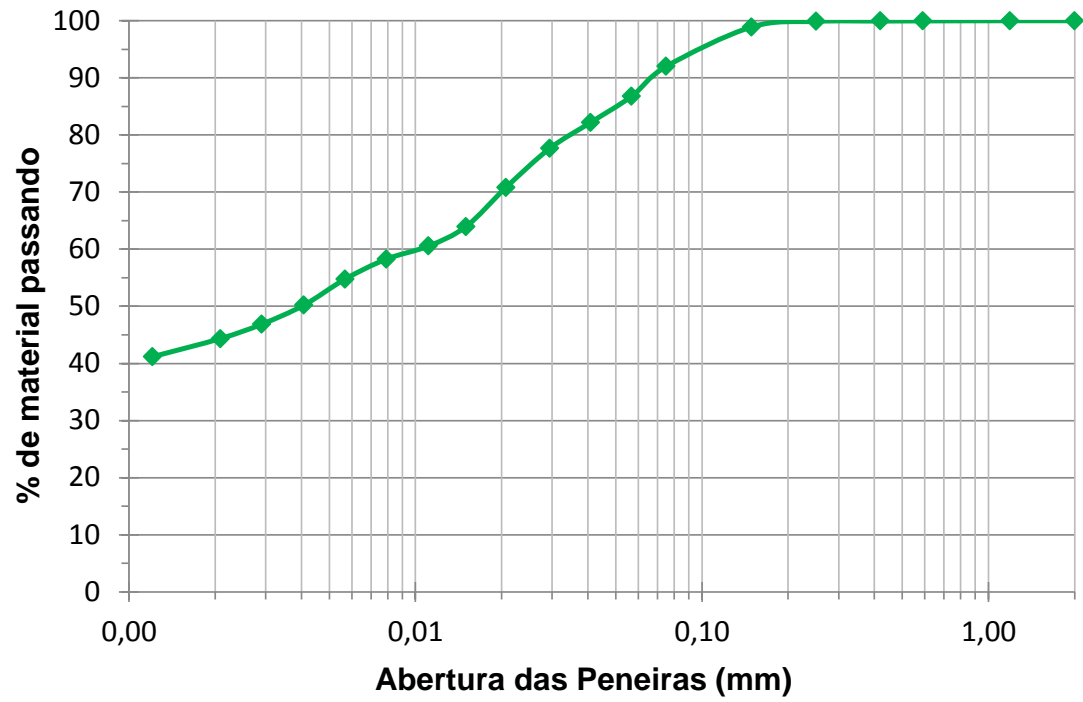

Figura 2: Curva granulométrica do material argiloso.

A Tabela 2 lista os limites de consistência e o índice de plasticidade (IP) da aludida amostra. Particularmente, o valor deste parâmetro atende ao percentual maior que $15 \%$ para confecção de agregados calcinados, segundo o DNIT [22]. O conjunto dos valores do limite de liquidez, limite de plasticidade e a granulometria resultaram na classificação A7-6, segundo o critério da American Association of State Highway and Transportation Oficial/Transportation Research Board (AASHTO/TRB), e como argila siltosa (CL), de acordo com o Sistema Unificado de Classificação dos Solos (SUCS).

Tabela 2: Índices de Consistência da amostra SUC.

\begin{tabular}{l|l}
\hline \multicolumn{1}{c|}{ PARÂMETRO } & \multicolumn{1}{c}{ RESULTADO } \\
\hline Limite de Liquidez (LL) & $48 \%$ \\
\hline Limite de Plasticidade (LP) & $22 \%$ \\
\hline Índice de Plasticidade (IP) & $26 \%$ \\
\hline IP mínimo (Frota et al., 2004a) & $>15 \%$ \\
\hline
\end{tabular}

Quanto ao ensaio de autoclave (DNER-ME 223/1994), a amostra SUC atendeu à mencionada norma, pelo fato de não ter variado o volume e a consistência, sendo, então, indicada para produção de ASAC. O mesmo ocorreu no teste de perda de massa (DNER-ME 225/1994), cujo resultado mostrou valor de 1,87\%.

Respeitante ao ensaio de Abrasão "Los Angeles", os resultados indicaram um desgaste da ordem de 70\%, acima do valor máximo igual a 45\%, prescrito pela norma DNER-EM 230/1994. Tal valor, a princípio, impediria o seu emprego como agregado graúdo em misturas asfálticas. Entretanto, trabalhos realizados pelo GEOTEC $[18,23]$ evidenciaram adequada resistência mecânica em composições com esse agregado de argila. Em particular, com menor potencial a desenvolverem deformações permanentes, relativas às tradicionais misturas com seixo, amplamente utilizados na construção dos pavimentos regionais. Portanto, deve-se aferir a viabilidade de uso do ASAC, não apenas quanto ao desgaste, mas, sobretudo, sob o prisma do comportamento mecânico. Ressalta-se, ainda, que pela citada norma, se admite, excepcionalmente, agregados graúdos com valores maiores a $45 \%$, no caso de terem mostrados, comprovadamente, desempenho satisfatório em anterior utilização.

\subsection{Caracterização dos agregados graúdos (seixo e ASAC)}

A Figura 3 ilustra a curva granulométrica e na Tabela 3 apresentam-se os resultados dos ensaios de caracterização para os agregados graúdos (ASAC e seixo). De acordo com a mencionada figura e dentro do que estabelece a NBR 6502/1995, os materiais ASAC e seixo mostram predominância média de suas frações, entre 6,0 e 20,0 mm. Pela Tabela 3 confere-se, por se tratar de um agregado leve, que o ASAC apresentou valores de massa específica (Aparente, Solta e Compactada) inferiores aos respectivos valores geralmente encontrados para os materiais naturais. $\mathrm{O}$ agregado alternativo também indicou um alto potencial quanto à absorção, $\mathrm{O}$ 
que pode ocasionar uma maior porcentagem de ligante no compósito asfáltico, dada a considerável porosidade frente à mistura confeccionada com agregado aluvionar [18]. Quanto ao desgaste por abrasão, somente o seixo atendeu às especificações, enquanto o agregado ASAC mostrou, como explanado, valor em desacordo com o normativo.

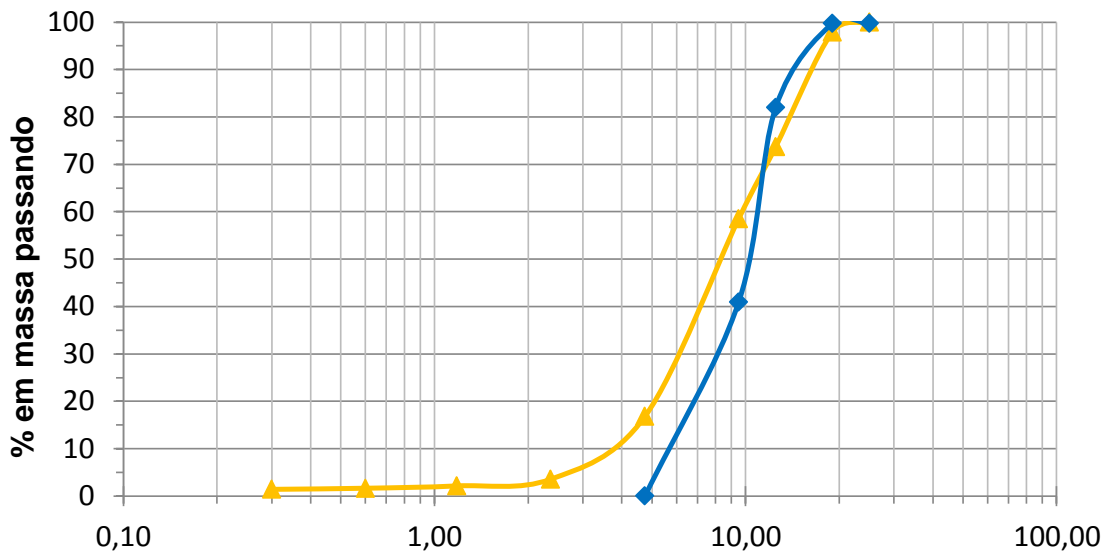

Abertura das Peneiras (mm)

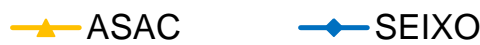

Figura 3: Curva granulométrica dos agregados graúdos.

Tabela 3: Caracterização dos agregados graúdos.

\begin{tabular}{c|l|l}
\hline \multirow{2}{*}{ PARÂMETRO } & \multicolumn{2}{c}{ AMOSTRA } \\
\cline { 2 - 3 } & \multicolumn{1}{|c}{ ASAC } & \multicolumn{1}{c}{ SEIXO } \\
\hline Gsb $\left(\mathrm{g} / \mathrm{cm}^{3}\right)$ & 1,855 & 2,626 \\
\hline Gsb ssd $\left(\mathrm{g} / \mathrm{cm}^{3}\right)$ & 2,133 & 2,636 \\
\hline Gsa $\left(\mathrm{g} / \mathrm{cm}^{3}\right)$ & 2,571 & 2,643 \\
\hline Absorption $(\%)$ & 15,03 & 0,0 \\
\hline Luw $\left(\mathrm{kg} / \mathrm{m}^{3}\right)$ & 1062,00 & 1894,60 \\
\hline Ruw $\left(\mathrm{kg} / \mathrm{m}^{3}\right)$ & 1126,35 & 1906,32 \\
\hline Abrasão Los Angeles $(\%)$ & 70,00 & 37,00 \\
\hline
\end{tabular}

\subsection{Caracterização dos agregados miúdos e fíler}

A Figura 4 ilustra as curvas granulométricas dos agregados miúdos (Areia Mao, Areia Coari e Areia ASAC) e do material de enchimento (cimento Portland). Observa-se, pela NBR 6502/1995, que a textura da areia de Manaus (Mao) predomina entre 0,2 e 0,6 mm (granulometria média); a Areia de Coari, apesar de possuir uma boa parcela de areia média, aproximadamente $40 \%$, mostra a fração areia grossa como dominante, cerca de $43 \%$ retida entre 0,6 e 2,0 mm; e atinente à areia artificial (Areia ASAC) sua fração areia grossa se sobressai sobre as demais, com um percentual próximo dos $37 \%$. Contudo, aproximadamente $35 \%$ do material ficou retido na peneira $\# 2,00 \mathrm{~mm}$, sendo classificada como uma areia pedregulhosa. Alusivo ao cimento verifica-se que esse passou integralmente na malha igual $0,075 \mathrm{~mm}$, atendendo ao requisito da especificação para uso do fíler. Tal integrante apresentou massa específica real igual $3,15 \mathrm{~g} / \mathrm{cm}^{3}$.

$\mathrm{Na}$ Tabela 4 constam os valores das massas específicas alusivas às areias Mao e Coari, que indicam correspondência com a sua matéria-prima (quartzo). Em particular, a Areia de ASAC, por originar-se de matéria-prima argilosa, apontou seus resultados inferiores aos respectivos parâmetros respeitantes às areias naturais (Mao e Coari). Nota-se, também, o alto valor do parâmetro absorção da areia proveniente do material calcinado. 


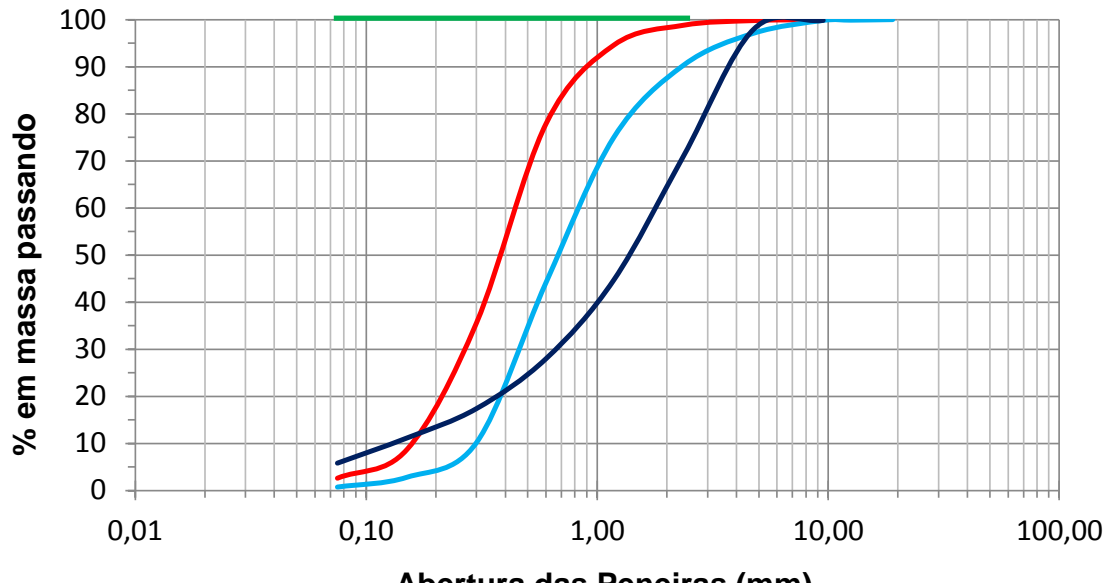

Abertura das Peneiras ( $\mathrm{mm})$

- Areia Mao Areia Coari Areia ASAC Cimento

Figura 4: Curvas granulométricas dos agregados miúdos e do fíler.

Tabela 4: Caracterização dos agregados miúdos.

\begin{tabular}{c|l|l|l}
\hline PARÂMETRO & \multicolumn{1}{|c|}{$\begin{array}{c}\text { AREIA } \\
\text { MAO }\end{array}$} & \multicolumn{1}{|c|}{$\begin{array}{c}\text { AREIA } \\
\text { COARI }\end{array}$} & \multicolumn{1}{c}{$\begin{array}{c}\text { AREIA } \\
\text { ASAC }\end{array}$} \\
\hline Gsb $\left(\mathrm{g} / \mathrm{cm}^{3}\right)$ & 2,632 & 2,627 & 1,790 \\
\hline Gsbssd $\left(\mathrm{g} / \mathrm{cm}^{3}\right)$ & 2,692 & 2,706 & 2,167 \\
\hline Absorption $(\%)$ & 0,0 & 0,0 & 18,96 \\
\hline Ruw $\left(\mathrm{kg} / \mathrm{m}^{3}\right)$ & 1675,9 & 1782,2 & 1375,71 \\
\hline
\end{tabular}

\subsection{Caracterização do ligante asfáltico}

Foi selecionado para a função ligante o cimento asfáltico de petróleo (CAP 50/70), oriundo dos petróleos Ceará-mar (Ceará) e Campo Fazenda Alegre (Espírito Santo). Tal escolha decorre do fato desse material betuminoso ser majoritariamente empregado e comercializado em Manaus. Foi caracterizado pela Refinaria Isaac Sabbá (REMAN) segundo as especificações estabelecidas pela Agência Nacional de Petróleo, Gás Natural e Biocombustíveis (ANP), que por sua vez utiliza as normas da American Society of Testing and Materials (ASTM), cujos resultados são apresentados na Tabela 5.

Tabela 5: Caracterização do cimento asfáltico de petróleo.

\begin{tabular}{|c|c|c|c|}
\hline CARACTERÍSTICAS & UND & CAP 50/70 & MÉTODO \\
\hline Penetração $\left(100 \mathrm{~g}, 5 \mathrm{~s}, 25^{\circ} \mathrm{C}\right)$ & $0,1 \mathrm{~mm}$ & 50 a 70 & ASTM D 5 \\
\hline Ponto de amolecimento, min. & ${ }^{\circ} \mathrm{C}$ & 46 & ASTM D 36 \\
\hline \multicolumn{4}{|c|}{ VISCOSIDADE SAYBOLTFUROL } \\
\hline a $135^{\circ} \mathrm{C}$, min. & $\mathrm{s}$ & 141 & \multirow{3}{*}{ ASTM E 102} \\
\hline a $150{ }^{\circ} \mathrm{C}, \min$. & $\mathrm{s}$ & 50 & \\
\hline a $170^{\circ} \mathrm{C}$ & $\mathrm{s}$ & 30 a 150 & \\
\hline \multicolumn{4}{|c|}{ VISCOSIDADE BROOKFIELD } \\
\hline a $135^{\circ} \mathrm{C}$, min. & $\mathrm{cP}$ & 274 & \multirow{3}{*}{ ASTM D 4402} \\
\hline a $150{ }^{\circ} \mathrm{C}$, min. & $\mathrm{cP}$ & 112 & \\
\hline a $177^{\circ} \mathrm{C}, \min$. & $\mathrm{cP}$ & 57 a 285 & \\
\hline $\begin{array}{l}\text { Índice de suscetibilidade tér- } \\
\text { mica }\end{array}$ & & $(-1,5)$ a $(+0,7)$ & - \\
\hline Ponto de fulgor min. & ${ }^{\circ} \mathrm{C}$ & 235 & ASTM D 92 \\
\hline
\end{tabular}




\begin{tabular}{c|c|c|c}
\hline $\begin{array}{c}\text { Solubilidade em tricloroetile- } \\
\text { no, min. }\end{array}$ & $\%$ massa & 99,5 & ASTM D 2042 \\
\hline Ductilidade a $25^{\circ} \mathrm{C}$, min. & $\mathrm{cm}$ & 60 & ASTM D 113 \\
\hline \multicolumn{2}{c|}{ EFEITO DO CALOR E DO AR A $\mathbf{1 6 3}{ }^{\circ} \mathbf{C}$ POR 85 MIN } \\
\hline Variação em massa, máx. & $\%$ massa & 0,5 & ASTM D 2872 \\
\hline $\begin{array}{c}\text { Ductilidade a } 25^{\circ} \mathrm{C}, \text { min. } \\
\text { Aumento do ponto de amole- } \\
\text { cimento }\end{array}$ & $\mathrm{cm}$ & 20 & ASTM D 113 \\
\hline Penetração retida, min. & $\%$ & 8 & ASTM D 36 \\
\hline
\end{tabular}

\subsection{Caracterização da mistura asfáltica do tipo Concreto Asfáltico (CA)}

A composição das misturas asfálticas é mostrada na Tabela 6. Visando o arranjo mineral, foi empregado o método de Bailey de seleção granulométrica, além do enquadramento da textura na faixa Superpave com DMN de 19,0 mm. Observa-se, pela Figura 5, que todas as misturas, conforme recomendado, passaram além da Zona de Restrição (ZR) e entre os Pontos de Controles (PC). Constatou-se que a mistura asfáltica com seixo é considerada como fina (acima da Zona de Restrição) e o compósito com ASAC como grossa (abaixo da Zona de Restrição). Encontrou-se o teor de projeto em 9,40\% e 4,5\% para as misturas com ASAC e as composições com seixo, respectivamente. Confrontando esses percentuais, ressalta-se que o menor valor para a formulação com agregado natural relativo ao compósito com ASAC, deve-se ao fato deste agregado alternativo mostrar um alto índice de absorção.

Tabela 6: Composição das misturas do Tipo CA.

\begin{tabular}{c|l|l}
\hline \multirow{2}{*}{ COMPONENTES } & \multicolumn{2}{|c}{ MISTURA ASFÁLTICA } \\
\cline { 2 - 3 } & \multicolumn{1}{|c}{ ASAC } & \multicolumn{1}{c}{ SEIXO } \\
\hline ASAC & $74,25 \%$ & - \\
\hline Seixo & - & $67,20 \%$ \\
\hline Areia ASAC & $14,03 \%$ & - \\
\hline Areia Coari & $10,32 \%$ & - \\
\hline Areia Mao & - & $29,70 \%$ \\
\hline Cimento Portland & $1,40 \%$ & $3,10 \%$ \\
\hline
\end{tabular}

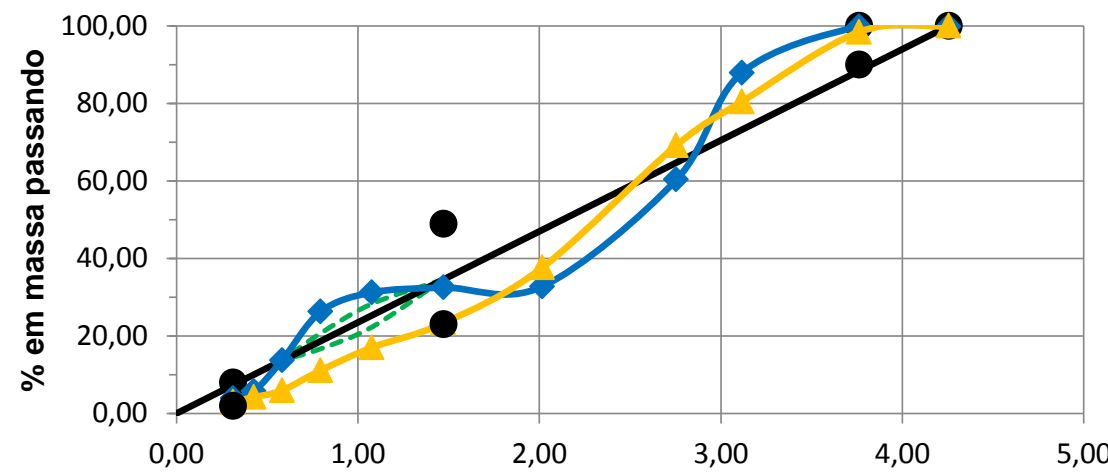

Abertura das peneiras elevada à potência $0,45(\mathrm{~mm})$

- Pontos de Controle Zona de Restição Densidade Máxima $\longrightarrow$ Seixo ASAC

Figura 5: Curvas granulométricas das misturas (CA/Seixo e CA/ASAC). 


\subsection{Resistência à Tração}

A Figura 6 exibe os valores de resistência à tração por compressão diametral para diferentes temperaturas. Observa-se a influência da condição de campo (altas temperaturas) em relação a esse parâmetro. A mistura confeccionada com o seixo indica maiores valores da RT para temperaturas até $40^{\circ} \mathrm{C}$, quando, então, começa a perder resistência devido à falta de aderência de suas partículas, de superfície polida, com o ligante aquecido. Acima daquela temperatura as composições com ASAC, apresentam maiores valores de RT devido ao maior atrito entre suas partículas. É possível notar que na temperatura de $25^{\circ} \mathrm{C}$ as misturas pesquisadas possuem resistência maior que $0,65 \mathrm{MPa}$, como recomenda a especificação brasileira para concretos asfálticos (DNIT 031/2006-ES). Ressalta-se ainda que os valores da RT expõem uma maior variação até próximo da faixa de $40^{\circ} \mathrm{C}$ a $45^{\circ} \mathrm{C}$. Em temperaturas superiores o ligante asfáltico se apresenta tão viscoso que não desempenha mais satisfatoriamente a função de unir os agregados. Observa-se, também, que os acréscimos na temperatura, a partir de $45^{\circ} \mathrm{C}$, não acarretam grandes variações na RT, principalmente para o caso da mistura com ASAC. Comparando com os resultados encontrados na literatura para a temperatura de $25^{\circ} \mathrm{C}$, a $\mathrm{RT}$ da mistura confeccionada com agregado de argila desta pesquisa (1,08 MPa) superou em 10,20\% [24], 14,89\% [25] e 66,15\% [26] os respectivos valores médios obtidos nas misturas de concreto asfáltico, com simulação de envelhecimento, produzidas nos citados estudos. Ressalta-se que a mistura da pesquisa em pauta com ASAC proporciona superioridade em $118,18 \%$ e $136,36 \%$, às temperaturas de $30^{\circ} \mathrm{C}$ e $35^{\circ} \mathrm{C}$, em confronto com as misturas do citado estudo [26]. Os outros trabalhos, também mencionados [24, 25], não mostram valores de RT nessas temperaturas.

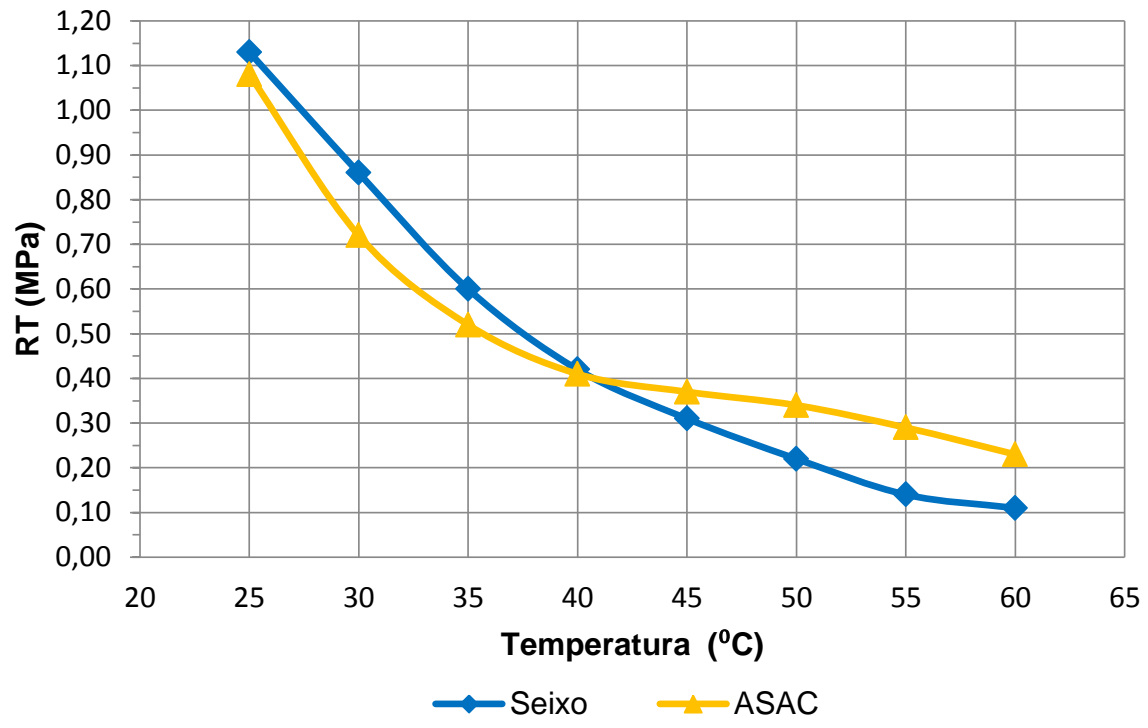

Figura 6: Resistência à Tração em função da temperatura.

\subsection{Módulo de Resiliência}

As Figuras 7 a 9 mostram os Módulos de Resiliência no intervalo de temperaturas de $25^{\circ} \mathrm{C}$ a $60^{\circ} \mathrm{C}$, com variação intermediária de $5 \mathrm{em} 5^{\circ} \mathrm{C}$, e calculados a partir da aplicação de diferentes níveis de tensão. Determinouse o valor desse parâmetro a partir de $40^{\circ} \mathrm{C}$, embora ciente que acima desta temperatura as propriedades viscosas do ligante passam a predominar no comportamento das composições, ou seja, para essas temperaturas, tais misturas encontram-se fora do regime elástico. 


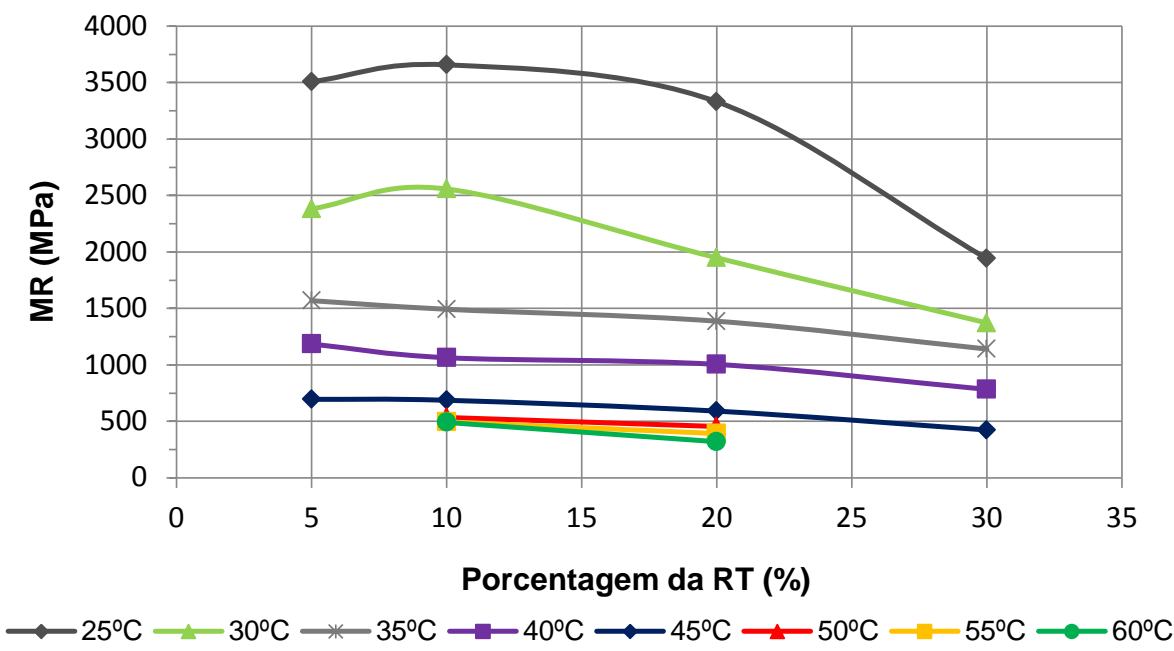

Figura 7: Módulo de Resiliência da mistura com seixo em função da temperatura da porcentagem de RT.

A mistura composta com seixo apresentou-se bastante suscetível a ação da temperatura, como se observa na Figura 7. Nota-se que o MR exibe uma sensível variação com o nível de tensão aplicada em menores temperaturas $\left(25^{\circ} \mathrm{C}\right.$ e $\left.30^{\circ} \mathrm{C}\right)$. No intervalo de tensões de $5 \%$ a $20 \%$ da RT, o MR é praticamente constante para a temperatura de $25^{\circ} \mathrm{C}$, em torno de $3.500 \mathrm{MPa}$. Porém, o aumento da carga para $30 \%$ da RT causa uma considerável diminuição desse parâmetro para aproximadamente $2.000 \mathrm{MPa}$, sugerindo que sob esse nível de tensão a mistura não se encontra mais dentro do regime elástico. Para a temperatura de $30^{\circ} \mathrm{C}$ e tensões até $20 \%$ da RT, tem-se o valor de MR entre 2.000 e $2.500 \mathrm{MPa}$. Para temperaturas superiores a $35^{\circ} \mathrm{C}$ o Módulo de Resiliência apresenta pequenas variações.

Não foi possível ensaiar essa composição com tensões correspondentes a $5 \%$ da RT a partir de $50^{\circ} \mathrm{C}$, devido ao pequeno valor de carga ser menor que o fundo de escala do equipamento $(100 \mathrm{~N})$. Para as tensões relativas a $30 \%$ da RT e nessas temperaturas, ocorreram grandes deformações, visíveis a olho nu, antes mesmo do término da fase de condicionamento. Em resumo, o Módulo de Resiliência dos compósitos com material aluvionar apresentou grandes variações entre $25^{\circ} \mathrm{C}$ a $35^{\circ} \mathrm{C}$, uma menor diferença na faixa de $35^{\circ} \mathrm{C}$ a $45^{\circ} \mathrm{C}$, e praticamente não alterou de $45^{\circ} \mathrm{C}$ a $60^{\circ} \mathrm{C}$, permanecendo com valor em torno de $500 \mathrm{MPa}$ para este último intervalo de temperatura.

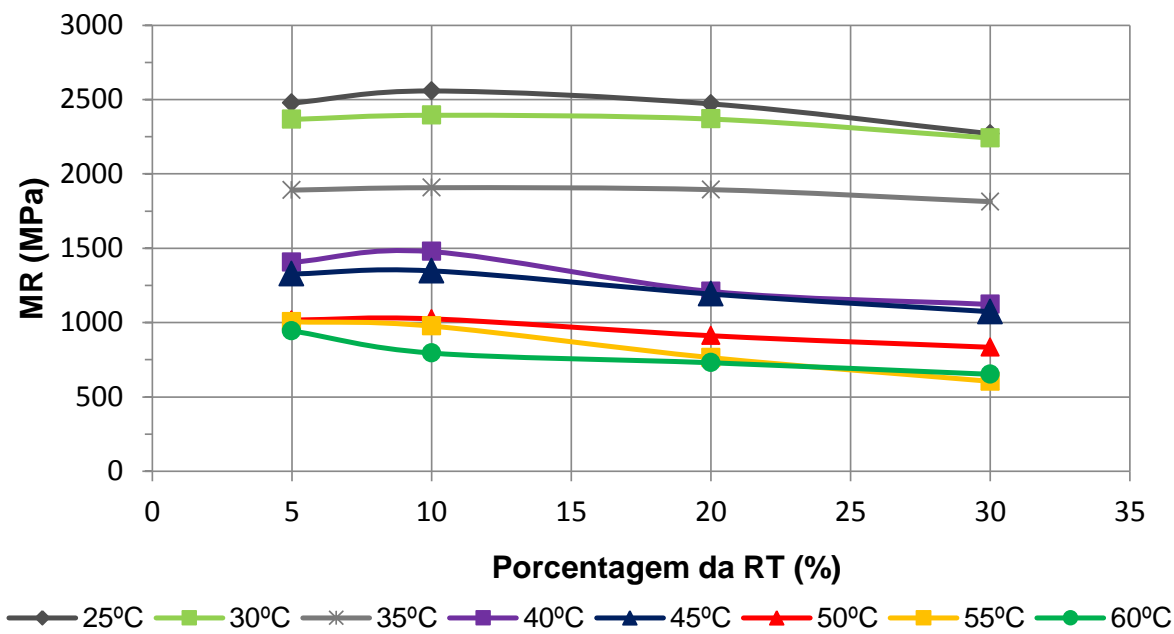

Figura 8: Módulo de Resiliência da mistura com ASAC em função da temperatura de da porcentagem de RT. 
Conforme mostrado na Figura 8, que ilustra o Módulo de Resiliência da mistura com ASAC em função da temperatura de da porcentagem de RT a mistura com ASAC apresenta o MR praticamente constante para diferentes tensões e temperaturas, concluindo-se que o compósito é pouco suscetível à variação de temperatura. Este tipo de mistura indica, tal como as demais, perda em suas propriedades, à medida que aumenta a temperatura. Entretanto, é a composição que se mantém mais resistente com o aumento da temperatura. $\mathrm{O}$ mencionado parâmetro apresenta variações intermediárias a temperaturas entre $25^{\circ} \mathrm{C}$ a $50^{\circ} \mathrm{C}$, e praticamente não altera na faixa de $50^{\circ} \mathrm{C}$ a $60^{\circ} \mathrm{C}$.

$\mathrm{Na}$ quase totalidade das misturas ensaiadas, seja com ASAC ou seixo, e para o intervalo de temperaturas especificado, nota-se, pelas Figuras 7 e 8, que níveis muito pequenos de tensões, como 5\% da RT, resultaram em valores de MR diferenciados daqueles obtidos com tensões maiores, mesmo obedecendo ao regime elástico. Sendo assim, como recomendado pela norma DNER ME 133 (1994), adotou-se o menor valor de carga capaz de gerar registros mensuráveis para a determinação do Módulo de Resiliência, ou seja, a carga em torno de $10 \%$ da RT. Essa tensão mostrou sempre boas leituras para todas as misturas e em todas as temperaturas pesquisadas.

Resumem-se na Figura 9 os dados presentes nos gráficos das figuras 7 e 8. Observa-se que, em geral, a partir de $30^{\circ} \mathrm{C}$, os compósitos com ASAC apresentam os maiores valores do MR comparados às misturas com o Seixo. Também, como nos resultados para Resistência à Tração, a partir de $45^{\circ} \mathrm{C}$, o Módulo de Resiliência varia de forma discreta, sendo provável que sob tais temperaturas o desempenho das misturas seja governado pelas características viscosas do CAP. Destaca-se que os valores de $\mathrm{MR}$ a $25^{\circ} \mathrm{C}(2558 \mathrm{MPa}), 30^{\circ} \mathrm{C}$ (2395 $\mathrm{MPa})$ e $35^{\circ} \mathrm{C}(1907 \mathrm{MPa})$, para as misturas de concreto asfáltico com argila calcinada, suplantaram os resultados em 22,63\%, 124,25\% e 144,49\%, respectivamente, dos resultados constantes na literatura [26]. Salienta-se que durante a revisão bibliográfica para prosseguimento dessa linha comparativa, não foram encontradas pesquisas com valores de MR para as demais temperaturas estudadas no presente estudo.

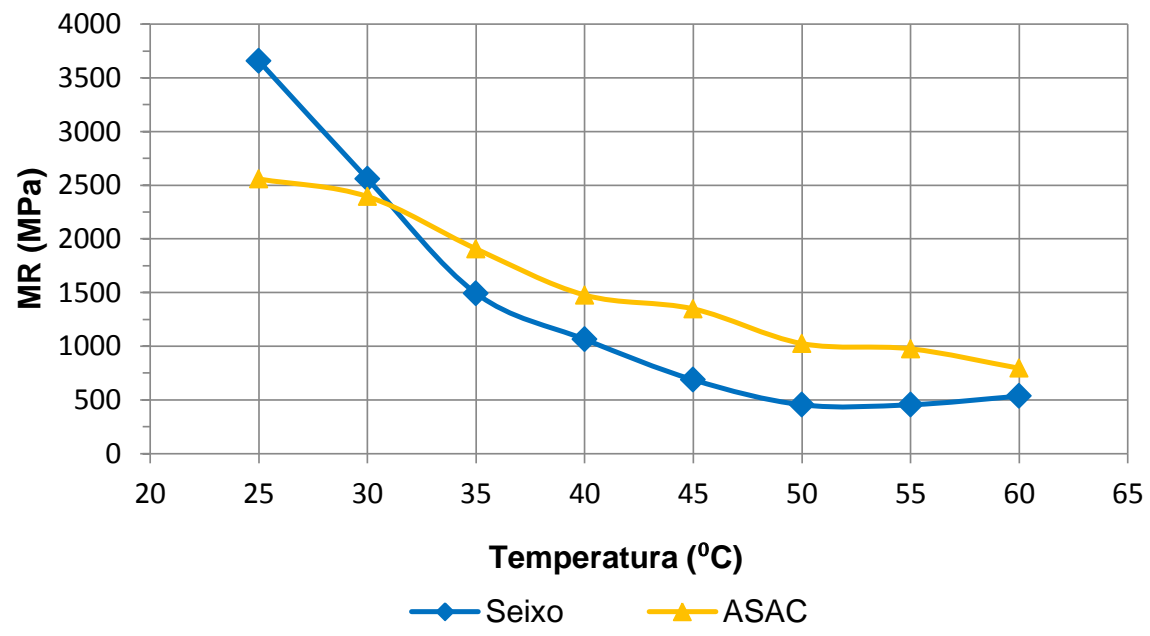

Figura 9: Módulo de Resiliência em função da temperatura das misturas com seixo e ASAC.

\subsection{Vida de Fadiga}

Por meio do Fator Laboratório-Campo (FLC) é possível relacionar o número "N", obtido a partir do tráfego previsto em projeto rodoviário, com o "N" determinado no ensaio de Vida de Fadiga, devido às dificuldades de simular as condições reais do campo nos experimentos laboratoriais. As Figuras 10 e 11 mostram as curvas de Vida de Fadiga das composições para diferentes temperaturas. Nota-se, para todos os compósitos, sob um determinado nível de tensão, que com o aumento da temperatura é necessário um menor número de repetições de carga para que ocorra a ruptura. Destaca-se o comportamento de perda das propriedades elásticas das misturas a altas temperaturas. Constata-se também que, para os níveis de tensão estudados, em regra, a composição com ASAC indicou maior resistência em todas as temperaturas em relação à mistura com seixo. 


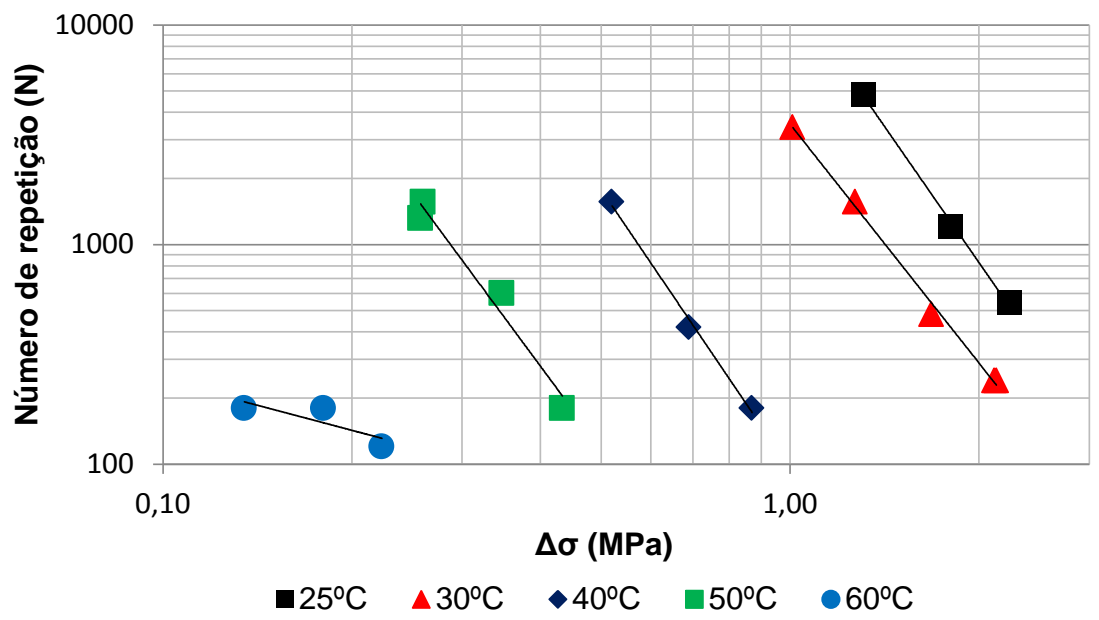

Figura 10: Vida de Fadiga para a mistura com seixo.

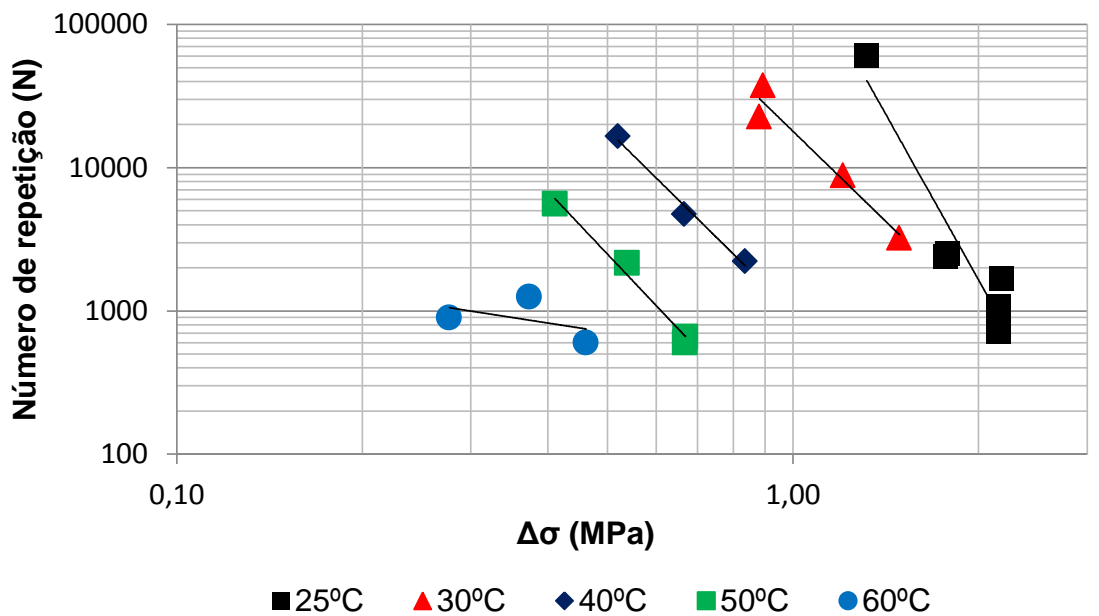

Figura 11: Vida de Fadiga para a mistura com ASAC.

\section{CONCLUSÕES}

Ao se analisar o comportamento das misturas asfálticas do tipo CA, considerando as diferentes temperaturas e, em particular, aquelas ocorrentes nos revestimentos da Região, chega-se às seguintes conclusões:

a) As propriedades mecânicas das composições asfálticas mostraram grande influência da temperatura de serviço alusivo à Resistência à Tração, ao Módulo de Resiliência e à Vida de fadiga;

b) Os valores da Resistência à Tração, para ambas as misturas asfálticas (alternativa e a referência), foram maiores que 0,65 $\mathrm{MPa}$, atendendo, portanto, a norma para os concretos asfálticos;

c) São recomendadas para o cálculo do Módulo de Resiliência cargas que gerem tensões entre $10 \%$ e $20 \%$ da RT, uma vez que apresentam boa leitura das deformações e permanecem dentro do regime elástico;

d) Nos resultados de MR, percebe-se que até os $30^{\circ} \mathrm{C}$, a mistura asfáltica com seixo indicou os melhores resultados. Porém, em temperaturas superiores, a composição com ASAC superou os valores desse parâmetro para todas as faixas de temperatura;

e) Nos resultados de Vida de fadiga, à medida que a temperatura cresceu, observou-se um menor número de repetições de carga;

f) Para todas as temperaturas, no ensaio de Vida de fadiga, o número de repetições de carga para rompimento da amostra contendo ASAC mostrou-se superior, confrontada com a mistura com seixo, a indicar, assim, um melhor desempenho mecânico; 
g) Na composição com ASAC, verificaram-se os melhores resultados, quanto à Resistência à Tração, bem como a constância no Módulo de Resiliência, com o aumento de cargas, e a superioridade da Vida de fadiga para as temperaturas ensaiadas.

Pelo exposto, os resultados dos ensaios mecânicos evidenciaram desempenho satisfatório das misturas asfálticas com ASAC, em cotejo com as composições com seixo. Tal conclusão contribui para ratificar que a utilização de agregados de argila calcinada podem ser uma alternativa ao seixo para a produção de misturas asfálticas.

\section{BIBLIOGRAFIA}

[1] LOSA, M., LEANDRI, P. AND BACCI, R., "Mechanical and Performance-Related Properties of Asphalt Mixes Containing Expanded Clay Aggregate", Transportation Research Record, v.2051, pp. 23-30, 2008.

[2] LEHMANN, H.L. AND ADAM, V., "Use of Expanded Clay Aggregate in Bituminous Construction", Highway Research Board Proceedings, v.38, pp. 398-407, 1959.

[3] MALLICK, R.B., HOOPER, F.P., et al., "Evaluation of Use of Synthetic Lightweight Aggregate in HotMix Asphalt”, Transportation Research Record, 1891.1, pp. 1-7, 2004.

[4] CANESTRARI, F.M., BOCCI, G., et al., "Mechanical Characterization of Environmentally Friendly Mixtures", In: Proceeding of the International Conference on Advanced Characterization of Pavement and Soil Engineering Materials, pp. 1643-1652, Greece, Jun. 2007.

[5] SHENA, D.H., WUA, C.W., CHONG, D.J.C., "Performance Evaluation of Porous Asphalt with Granulated Synthetic Lightweight Aggregate”, Construction and Building Materials, 22, pp. 902-910, 2008.

[6] TAY, J.H., "Brick Manufactured from Sludge", Journal of Environmental Engineering, v.113, pp. 278284, 1987.

[7] CHURCHILL, M., “Aspect of Sewage Sludge Utilization and its Impact on Brick Making”, Global Ceramic Review, v.1, pp. 18-21, 1994.

[8] PEREZ, J.A, TERRADAS, R., et al., "Inertization of Industrial Wastes in Ceramic Materials", Industrial Ceramics, v. 16, n.1, pp. 7-10, 1996.

[9] ALLEMAN, J.E., "Beneficial Use of Sludge in Building Components”, Interbrick, v.3, pp. 14-16, 1987.

[10] RIBERIO, M.J., TULYAGANOV, D.U., et al., "Recycling of Al-Rich Industrial Sludge in Refractory Ceramic Pressed Bodies”, Ceramics International, v. 28, pp. 319-326, 2002.

[11] ZBOROWSKI, A., SOTIL, A., et al., "Material Characteristics of Asphalt Rubber Mixtures", In: Proceedings of 83rd TRB Annual Meeting, pp. 11-15, Washington DC, Jan. 2004.

[12] SANTAGATA, F.A., CANESTRARI, F., PASQUINI, E., "Mechanical Characterization of Asphalt Rubber-Wet Process", In: Proceedings of 4th International SIIV Congress - Advances in Transportation Infrastructures and Stakeholders Expectation, pp. 12-14, Palermo, Sep. 2007.

[13] BENTO, A. H., FROTA, C. A., “Mapeamento Geotécnico da Área Urbana de Manaus - AM”, In: Anais do Simpósio Brasileiro de Cartografia Geotécnica, III, Florianópolis, 1998.

[14] CNT, Pesquisa CNT de Rodovias, In: Relatório Gerencial: Condeferação Nacional de Transportes, SEST, SENAT, Brasília, 2016.

[15] VIEIRA, A., “Agregados de argila calcinada: uma alternativa para a pavimentação rodoviária na região amazônica”, In: Anais da Reunião Anual de Pavimentação, 32, Brasília, 2000.

[16] NASCIMENTO, R. R., Utilização de Agregados de Argila Calcinada em Pavimentação: Uma Alternati-va para o Estado do Acre, Dissertação de M. Sc., Universidade Federal do Rio de Janeiro, RJ, Brasil, 2005.

[17] FROTA, C. A., SILVA, C. L., NUNES, F. R. G., "Análise do Comportamento Mecânico de Misturas Asfálticas Confeccionadas com Agregados Sintéticos de Argila Calcinada", In: Anais das Jornadas LusoBrasileiras de Pavimentos: Políticas e Tecnologias, 5, Recife, 2006.

[18] FROTA, C. A., NUNES, F. R. G., SILVA, C. L., et al., "Desempenho mecânico de misturas asfálticas confeccionadas com agregados sintéticos de argila calcinada”, Cerâmica, v.3, pp. 255-262, Set. 2007.

[19] SANTOS, R. A., VIEIRA, A., OLIVEIRA, J. R. M. S., et al., "Produção de agregado artificial de argila calcinada para emprego em pista experimental no estado do Rio de Janeiro" In: Anais da Reunião Anual de Pavimentação/ Encontro Nacional de Conservação Rodoviária, 38, Manaus, AM, Ago. 2007. 
[20] SILVA, C. L., FROTA, H.O., FROTA, C.A., "Sintered Calcined Clay as an Alternative Coarse Aggregate for Asphalt Pavement Construction”, Open Journal of Civil Engineering, v.5, n.3, pp. 281-288, Sep. 2015.

[21] SILVA, A. C. L., FROTA, C. A., "Estudo da viabilidade econômica para produção de agregado sinteriza-do de argila calcinada", Cerâmica, v.59, n.352, pp. 508-517, Abr./Jun. 2013.

[22] FROTA, C. A., SILVA, C. L., NUNES, F. R. G., "Estudo da exploração de argila para fins de calcinação, visando a construção de pavimentos na província petrolífera de Urucu-AM-Brasil”, In: Anais do congreso V Jornadas Luso-Brasileiras de pavimentos: Políticas e Tecnologias, v. 46, Recife, 2006.

[23] SILVA, C. L.A, SILVA, C.L., et al., "Processo produtivo de agregados sinterizados de argila calcinada para a região Amazônica”, Estudos Tecnológicos, v. 5, n. 3, pp. 374-388, 2009.

[24] SANTOS, R.A., Avaliação do emprego de agregado artificial de argila calcinada em pavimentação, Dissertação de M.Sc., Instituto Militar de Engenharia- IME, Rio de Janeiro, RJ, Brasil, 2008.

[25] SILVA, M.A.V., Comportamento de misturas asfálticas a quente utilizando agregado de argila calcinada, Dissertação de M.Sc., Instituto Militar de Engenharia/IME, Rio de Janeiro, RJ, Brasil, 2006.

[26] BATISTA, F. G. S., Caracterização física e mecanística dos agregados de argila calcinada produzidos com solos finos da BR-163/PA, Dissertação de M.Sc., Instituto Militar de Engenharia/IME, Rio de Janeiro, RJ, Brasil, 2004. 